\section{Social context of neighborhood and socioeconomic status on leisure-time physical activity in a Brazilian urban center: The BH Health Study}

\section{Contexto social de moradia na prática de atividade física no lazer de residentes de um centro urbano: Estudo Saúde em Beagá}

\section{El contexto social del barrio en la práctica de actividad física durante el tiempo libre de los residentes de un centro urbano: Estudio Salud en Beagá}

\author{
Amanda Cristina de Souza Andrade 1,2 \\ Sérgio Viana Peixoto 3,4 \\ Amélia Augusta de Lima Friche 1,2 \\ Janaína Lavalli Goston 1,2 \\ Cibele Comini César 5 \\ César Coelho Xavier 2,6 \\ Fernando Augusto Proietti 3,6 \\ Ana V. Diez Roux 7 \\ Waleska Teixeira Caiaffa 1,2
}

\footnotetext{
${ }^{1}$ Faculdade de Medicina, Universidade Federal de Minas Gerais, Belo Horizonte, Brasil.

2 Observatório de Saúde Urbana de Belo Horizonte, Belo Horizonte, Brasil. 3 Centro de Pesquisas René Rachou, Fundação Oswaldo Cruz, Belo Horizonte, Brasil. 4 Escola de Enfermagem, Universidade Federal de Minas Gerais, Belo Horizonte, Brasil.

5 Instituto de Ciências Exatas, Universidade Federal de Minas Gerais, Belo Horizonte Brasil.

6 Faculdade de Saúde e Ecologia Humana, Vespasiano, Brasil. 7 School of Public Health, Drexel University Philadelphia, U.S.A.

Correspondence A. C. S. Andrade Observatório de Saúde Urbana de Belo Horizonte. Av. Alfredo Balena 190, Belo Horizonte, MG 30130-100, Brasil.

amandasouza_est@yahoo.com.br
}

\begin{abstract}
This study aimed to estimate the prevalence of leisure-time physical activity and investigate its association with contextual characteristics of the social and physical environment in different socioeconomic statuses, using a household survey in Belo Horizonte, Minas Gerais State, Brazil (2008-2009). Leisure-time physical activity was measured by the International Physical Activity Questionnaire; and the social and physical environment by scales arising from perception of neighborhood attributes. Multilevel logistic regression analysis was performed separately for each socioeconomic status stratum. The overall prevalence of leisure-time physical activity was $30.2 \%$, being $20.2 \%$ amongst participants of low socioeconomic status, $25.4 \%$ in the medium and $40.6 \%$ in the high socioeconomic status group. A greater perception of social cohesion was associated with increased leisure-time physical activity only amongst participants of the lowest socioeconomic status even after adjusting for individual characteristics. The results demonstrate the importance of social cohesion for the promotion of leisure-time physical activity in economically disadvantaged groups, supporting the need to stimulate interventions for enhancing social relationships in this population.
\end{abstract}

Motor Activity; Leisure Activities; Environment; Urban Health

\section{Resumo}

Este estudo teve como objetivo estimar a prevalência de atividade física de lazer e investigar sua associação com características contextuais do ambiente social e físico, em diferentes níveis socioeconômicos, utilizando inquérito domiciliar realizado em Belo Horizonte, Minas Gerais, Brasil (2008-2009). A atividade física de lazer foi mensurada por meio do Questionário Internacional de Atividade Física, e o ambiente social e físico por escalas originadas da percepção dos atributos da vizinhança. Foram realizadas análises de regressão logística multinível para cada estrato de níveis socioeconômicos. A prevalência geral de atividade física de lazer foi de 30,2\%, sendo 20,2\% no nível socioeconômico baixo, 25,4\% no médio e 40,6\% no nível socioeconômico alto. Maior percepção de coesão social na vizinhança foi associada à atividade física de lazer apenas para o estrato socioeconômico mais baixo, mesmo após o ajuste pelas características individuais. Os resultados evidenciam a importância da coesão social para a promoção da prática de atividade física de lazer em grupos economicamente mais desfavorecidos, reforçando a necessidade de se estimular ações que possam incrementar as relações sociais nesta população.

Atividade Motora; Atividades de Lazer; Meio Ambiente; Saúde Urbana 


\section{Introduction}

Public health recommendations have emphasized the importance of physical activity in various aspects of daily life, such as leisure, housework, work and travel. Leisure-time physical activity has been found to be strongly linked to a number of health outcomes 1,2,3. Despite the well-known benefits of an active lifestyle, the physically active portion of the population remains small 1,4 .

Studies show that strategies aimed at addressing only individual barriers to physical activity have limited success 5. Furthermore, evidence suggests that social factors (interpersonal relationships and social networks), along with physical attributes of the environment can influence the physical activity pattern of the population 1,6.

Research in developed countries shows that environmental characteristics are not only associated with general physical activity, but also with specific behaviors such as leisure activities, transportation, and walking 7,8,9,10. In Brazil, some studies have investigated the relationship between physical activity and the environment; however, the evidence supporting these associations is still limited 11,12,13,14,15,16,17.

The objective of this study was to estimate the prevalence of leisure-time physical activity among adult residents of a large city in Brazil and to investigate the associations of leisure-time physical activity with social and physical features of neighborhood environments with different socioeconomic profiles.

\section{Methods}

Data for this study was obtained through a household survey (The BH Health Study) conducted by the Belo Horizonte Observatory for Urban Health of the Federal University of Minas Gerais (UFMG) in 2008-2009. Two of the nine health districts of Belo Horizonte City, Oeste and Barreiro, were included in the study. These two districts comprise $24 \%$ of the $2,375,151$ residents of the city 18 . Belo Horizonte, capital of the state of Minas Gerais, Brazil, has an area of $331 \mathrm{~km}^{2}$, a population density of 7,177 residents $/ \mathrm{km}^{2} 18$ and a Human Development Index of 0.81019 . Residents of the two districts were sampled using a stratified three-stage cluster design (census tracts, household, and adult resident, 18 years or older). These districts were chosen because of their geographical proximity and internal heterogeneity in relation to various demographic, socioeconomic and health indicators. Census tracts were stratified using the
Health Vulnerability Index (HVI). The HVI is a census tract level indicator that combines information on social, demographic, economic and health indicators 20 . A total of 4,048 individuals responded to the survey 21,22 .

\section{Variables}

The dependent variable, leisure-time physical activity, was measured using the long version of the International Physical Activity Questionnaire (IPAQ). The IPAQ allows the evaluation of physical activity in a population and estimates the weekly time spent in moderate to vigorous physical activity within different contexts of life 23 . The weekly leisure physical activity score was calculated by adding the minutes spent per week in walking and in other physical activities classified as light, moderate or vigorous. According to previous recommendations, the time spent in vigorous physical activities was doubled before being added to the final score, in order to reflect its greater intensity 24 . For the score calculation, only activities lasting at least 10 consecutive minutes that occurred during the week immediately preceding the questionnaire administration were included. Individuals who received a score of $\geq 150$ minutes a week were considered physically active 25,26.

The National Wealth Score (IEN, in the Portuguese) was used as an indicator of socioeconomic position. The indicator was measured at the individual level and built up based on the information on household consumer goods and the schooling of the head of the household. As reported in the original study, the coefficients used to calculate this score were derived from a principal component analysis of a set of 13 variables from the Brazilian Demographic Census of 2000 27. Participants were categorized into three groups based on tertiles of the score: low ( $43 \leq$ score $\leq 490)$, medium $(491 \leq$ score $\leq 687)$ and high $(688 \leq$ score $\leq 1,066)$ socioeconomic statuses.

Neighborhood characteristics were measured using the perceived neighborhood scales proposed by Friche et al. 28, where estimates were derived by aggregating the responses for all participants within a census tract. The scores of the scales were generated from three-level models using empirical Bayes estimation, in order to account to inter-individual differences in responses to construct the aggregate measures, even within census tracts with small observations ${ }^{28}$. The aggregation process of individual environmental perceptions can result in a more valid measurement of neighborhood conditions and allow evaluation of the social environment, which cannot be measured by other techniques. 
For this study Services, Aesthetics, Safety and Social Cohesion scales were selected because they have been previously hypothesized to be related to physical activity 1,29,30. Elevated values on the scales represented favorable perceptions of the social and physical environment.

The Services scale was constructed based on evaluations of the following: street lighting; street and sidewalk maintenance; public locations for sport and leisure; public amenities; transportation; police services; traffic; and ease of accessing fresh, quality food. The Aesthetics domain included the following items: presence of trash or debris on the streets or neighborhood sidewalks; if the neighborhood is a pleasant place for children and teenagers; presence of trees and plants, which improve the environment. The Safety scale consisted of two items: sense of safety walking at night and if violence is a problem in the neighborhood. The items on the Social Cohesion scale refer to the social relationships among neighbors such as: trust neighbors to leave a key, to care for a family member during an emergency, and/ or lend items; neighbors who give advice, help financially and/or would inform you of interesting job opportunities 28 . For most questions, the responses were "yes" or "no", except for public services, with response options ranging from 1 to $4(1$ = very good, 2 = good, $3=$ bad, $4=$ very bad $)$.

The individual-level variables were grouped into three blocks: socio-demographic, lifestyle and health, and social support. The socio-demographic variables were age (years), sex (female or male), marital status (with a partner: married/ living together, or without a partner: single, separated/divorced, widowed), currently employed (yes or no), time living at the residence (years), educational attainment (0-4 years, 5-8 years, 9 - 11 years, and $\geq 12$ years) and family income as a multiple of the minimum monthly wage $(<2$, 2-3, 3-5, 5-10 and $\geq 10$ ). The health and lifestyle block included variables on regular consumption of fruit, natural fruit juice, and vegetables (regular fruit and vegetable consumption) categorized as $<5$ times/week and/or $\geq 5$ times/week; current smoker (yes or no: never smoked or ex-smoker); alcohol consumption (yes or no, determined by the question “Do you drink alcoholic beverages?”); self-perception of health (very good/good or reasonable/bad/very bad); body mass index (BMI) was classified as underweight $\left(<18.5 \mathrm{~kg} / \mathrm{m}^{2}\right)$, normal weight ( 18.5 to $\left.24.9 \mathrm{~kg} / \mathrm{m}^{2}\right)$ and overweight $\left(\geq 25.0 \mathrm{~kg} / \mathrm{m}^{2}\right)$ for adults 31 and underweight ( $\leq$ $\left.22.0 \mathrm{~kg} / \mathrm{m}^{2}\right)$, normal weight $\left(22.0\right.$ to $27.0 \mathrm{~kg} / \mathrm{m}^{2}$ ) and overweight $\left(\geq 27.0 \mathrm{~kg} / \mathrm{m}^{2}\right)$ for the elderly 32 .

The social support block included social participation 33 and physical activity social support 34 . For the former, principal component analysis was used to reduce the number of variables: How often in a month do you go to: 1. Bars, pubs, nightclubs or concerts; 2. Street or folk parties (free shows); 3. Recreational clubs or associations; 4. Soccer fields; 5. Movies; 6. Mall; 7. Theater; 8. Park, plaza or square; 9. Dance/cultural/ sports groups. The first principal component was adopted and categorized on tertiles: low, medium and high. For the latter, social support for physical activity, three questions (yes or no) were used: "If you need a ride to go to a location to participate in physical activity, can you count on someone from your neighborhood?" (Ride); "Do your friends and/or family members encourage you to be physically active?" (Encouragement from friends or family members); "Do you have at least one friend or family member committed to doing physical activity with you?" (Friends or family members' commitment).

\section{Statistical analysis}

We first conducted descriptive analysis of all variables by each set of socioeconomic status. The overall prevalence of leisure-time physical activity with the $95 \%$ confidence interval $(95 \% \mathrm{CI})$ was estimated for the population sample and for each socioeconomic status stratum. Because of the possibility that socioeconomic status could modify the associations of the environment with physical activity, multilevel models with a random intercept for each tract were fitted in each socioeconomic stratum 35,36 . The first level was represented by individuals and the second by the census tract. The census tract is a territorial unit collection of census operations, and defined by the Brazilian Institute of Geography and Statistics, with physical limits identified in continuous areas and respecting the political and administrative divisions of Brazil 18. The Intraclass Correlation Coefficient (ICC) was calculated as the latent variable method 35 .

First the null model was fitted (only the random intercept) to evaluate between neighborhood variability, then we added the neighborhood perception variables (scales of Services, Aesthetics, Safety and Social Cohesion) (Model 1). In the second model individual demographic variables were added. The third model included lifestyle and health variables; and the last model (Model 4) added individual social support variables. The analysis was adjusted for the main individual characteristics that may influence the association under study.

The software Stata, version 12.0 (StataCorp LP, College Station, USA) was used. All analyses were carried out taking the complex sample into account. A significance level of 5\% was used. 
This study was approved by the UFMG Ethics Research Committee (protocol number ETIC 253/006). All subjects provided written informed consent before participating in the research.

\section{Results}

The study included 3,597 individuals from 149 census tracts with a range of 6-39 individuals from each census tract. The overall prevalence of leisure-time physical activity was $30.2 \%$ (95\%CI: 27.3-33.1), with increasing rates from low to high socioeconomic status. It starts from $20.2 \%$ (95\%CI: 16.1-24.2) in the low; $25.4 \%$ (95\%CI: $21.9-28.8$ ) in the middle to $40.6 \%$ (95\%CI: $35.7-45.5$ ) in the high socioeconomic status stratum. For the overall population, the physical activities most reported were: walking (21.3\%), weight-lifting $(9.1 \%)$, team sports $(5.2 \%)$ and running (4.3\%). These activities were similarly prevalent within each socioeconomic status strata (data not shown).

The average age was 41 years old, $46.9 \%$ were female, $46.8 \%$ reported living without a partner, and $64.8 \%$ were employed at the time of the study. These characteristics did not differ by socioeconomic status strata. Individuals from the low socioeconomic status stratum reported shorter length of time living in their home, lower income and a lower level of education. The proportion of individuals with adequate regular fruit and vegetable consumption ( $\geq 5$ times/week), consumption of alcoholic beverages, the proportion overweight, and the proportion with good/ very good self-rated health were higher in persons of high socioeconomic status compared to those with low socioeconomic status. The proportion of smokers was higher in the low socioeconomic status than in the high socioeconomic status categories. Individuals of higher socioeconomic status stratum reported encouragement from friends or family members and greater social participation (Table 1).

The associations between leisure-time physical activity and neighborhood and individual characteristics stratified by socioeconomic status are shown in Tables 2 and 3. The average scores of the neighborhood scales ranged from 3.17 for Social Cohesion to 2.55 for Services (data not shown). In the univariate analysis, the Social Cohesion scale was positively associated with leisure-time physical activity within the low socioeconomic status stratum. Regardless of socioeconomic status, the Services, Aesthetics and Safety scales were not significantly associated with leisure-time physical activity (Table 2).

In the three socioeconomic status groups, physically active persons were more likely than inactive ones to be young, male, with a good/very good self-perceived health, with greater social participation and reported encouragement for physical activity from friends or family members. In the low socioeconomic status stratum they were also more likely to be currently employed and overweight. "Ride" was positively associated with leisure-time physical activity only within high socioeconomic status stratum. In the low and middle socioeconomic status brackets, physically active persons were more likely to consume fruit and vegetables, be a non-smoker, to not have a partner and to report company of friends or family members for physical activity. On the other hand, alcohol consumption was positively associated with physical activity in the middle and high socioeconomic status strata (Table 3 ).

Table 4 shows associations of individual and neighborhood factors with physical activity for each socioeconomic status category. Significant variability in leisure-time physical activity was found between neighborhoods (census tracts) in the null model. Leisure-time physical activity was associated with Social Cohesion scales for the low socioeconomic status stratum. Individuals living in neighborhoods with better perceptions of social cohesion $(\mathrm{OR}=1.43$; $95 \% \mathrm{CI}$ : 1.02 2.01) had higher odds of being physically active. No significant associations were observed between the Services, Aesthetics and Safety scales and leisure-time physical activity in any of the socioeconomic status strata (Model 4).

The addition of the neighborhood and individual variables changed the between tract variance as follows: reducing by $11 \%$ and $5.72 \%$ in low and high socioeconomic status strata, respectively, and increasing $4.34 \%$ in the middle socioeconomic status stratum (comparison between null model and model 4, Table 4). For all of the socioeconomic status strata, there was a reduction in the ICC when individual-level variables were added, suggesting that these variables contribute to between tract variability.

\section{Discussion}

This study aimed to investigate whether leisuretime physical activity is associated with perceptions of the social and physical living environment in different socioeconomic strata, and if this association remained after controlling for individual characteristics such as socio-demographics, health and lifestyle, and social support. Greater perceived social cohesion was associated with greater odds of leisure-time physical activity in the lowest socioeconomic stratum even after adjusting for individual characteristics. 
Table 1

Participant characteristics stratified by socioeconomic status. The BH Health Study, Belo Horizonte, Minas Gerais State, Brazil, $2008-2009$.

\begin{tabular}{|c|c|c|c|c|}
\hline \multirow[t]{3}{*}{ Variables } & \multirow{2}{*}{$\begin{array}{c}\text { Total } \\
(n=3,597)\end{array}$} & \multicolumn{3}{|c|}{ Socioeconomic status } \\
\hline & & $\begin{array}{c}\text { Low } \\
(n=1,224)\end{array}$ & $\begin{array}{c}\text { Medium } \\
(\mathrm{n}=1,203)\end{array}$ & $\begin{array}{c}\text { High } \\
(n=1,170)\end{array}$ \\
\hline & $\%$ or mean (SD) & $\%$ or mean (SD) & $\%$ or mean (SD) & $\%$ or mean (SD) \\
\hline Gender (male) & 46.9 & 43.7 & 47.2 & 48.8 \\
\hline Age (years) & $41.1(16.2)$ & $41.0(18.6)$ & $40.5(15.9)$ & $41.5(14.3)$ \\
\hline Marital status (without a partner) & 46.8 & 46.8 & 47.0 & 46.7 \\
\hline \multicolumn{5}{|l|}{ Education (years) * } \\
\hline $0-4$ & 19.8 & 37.3 & 20.5 & 7.7 \\
\hline $5-8$ & 21.7 & 29.9 & 25.8 & 13.0 \\
\hline $9-11$ & 36.4 & 30.2 & 42.2 & 36.0 \\
\hline$\geq 12$ & 22.1 & 2.6 & 11.5 & 43.0 \\
\hline \multicolumn{5}{|l|}{ Family income (minimum monthly wage - USD 240) * } \\
\hline$<2$ & 19.5 & 48.9 & 15.6 & 2.6 \\
\hline $2 \mid-3$ & 20.9 & 29.6 & 30.2 & 7.5 \\
\hline $3 \mid-5$ & 24.0 & 17.8 & 33.2 & 20.8 \\
\hline $5 \mid-10$ & 19.1 & 3.4 & 18.0 & 30.7 \\
\hline$\geq 10$ & 16.5 & 0.3 & 3.0 & 38.4 \\
\hline Currently working & 64.8 & 64.4 & 65.3 & 64.6 \\
\hline Time in neighborhood (years) * & $15.4(12.5)$ & $13.7(14.4)$ & $15.6(12.6)$ & $16.1(10.9)$ \\
\hline Regular fruit and vegetable consumption ( $\geq 5$ days/week) * & 48.6 & 39.9 & 45.9 & 48.6 \\
\hline Current smoker ** & 17.5 & 22.9 & 15.5 & 15.6 \\
\hline Alcohol consumption * & 47.7 & 37.8 & 40.8 & 59.8 \\
\hline \multicolumn{5}{|l|}{ 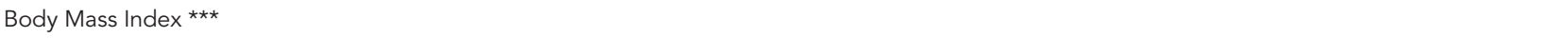 } \\
\hline Underweight & 5.9 & 8.6 & 6.3 & 3.8 \\
\hline Normal weight & 45.0 & 46.1 & 46.1 & 43.4 \\
\hline Overweight & 49.1 & 45.3 & 47.6 & 52.7 \\
\hline Self-perception of health (Good/Very good) * & 69.8 & 59.7 & 67.4 & 78.3 \\
\hline \multicolumn{5}{|l|}{ Social participation * } \\
\hline High & 38.9 & 22.5 & 33.6 & 53.9 \\
\hline Medium & 32.1 & 32.5 & 35.4 & 29.3 \\
\hline Low & 29.0 & 45.0 & 31.0 & 16.8 \\
\hline \multicolumn{5}{|l|}{ Physical activity social support } \\
\hline Ride & 37.2 & 34.6 & 38.8 & 37.7 \\
\hline Encouragement from friends or family members * & 68.8 & 56.8 & 69.4 & 76.1 \\
\hline Friends or family members' commitment & 58.2 & 54.8 & 59.8 & 59.1 \\
\hline Active during leisure * & 30.2 & 20.2 & 25.4 & 40.6 \\
\hline
\end{tabular}

SD: standard deviation.

Comparison between socioeconomic statuses: * $p<0,001$; ${ }^{* \star} p<0,05$; and ${ }^{* \star *} p<0,01$.

The prevalence of leisure-time physical activity found in this study was similar to results of a national survey of adults over 18 years of age in all Brazilian state capitals and the Federal District, where only $33.5 \%$ of the total sampled population and $36.4 \%$ of residents in Belo Horizonte were classified as active during leisure 26 . The regular practice of physical activity is of major importance in health promotion and disease prevention; however, indicators of this behavior remain low in the population 2 .

The results of this study are consistent with others showing that individuals in disadvantaged socioeconomic groups are less likely to be physically active during leisure-time than those of higher socioeconomic status 14,37. Recent studies in Brazil have shown that more education is positively associated with leisure-time physical 
Neighborhood and individual characteristics according to leisure-time physical activity classification, stratified by socioeconomic status. The BH Health Study, Belo Horizonte, Minas Gerais State, Brazil, 2008-2009.

\begin{tabular}{|c|c|c|c|c|c|c|}
\hline \multirow[t]{3}{*}{ Variables } & \multicolumn{6}{|c|}{ Socioeconomic status } \\
\hline & \multicolumn{2}{|c|}{ Low [mean (SD)] } & \multicolumn{2}{|c|}{ Medium [mean (SD)] } & \multicolumn{2}{|c|}{ High [mean (SD)] } \\
\hline & Active & Inactive & Active & Inactive & Active & Inactive \\
\hline Neighborhood & \multicolumn{2}{|c|}{$(n=138)$} & \multicolumn{2}{|c|}{$(n=145)$} & \multicolumn{2}{|c|}{$(n=143)$} \\
\hline Services & $2.54(0.23)$ & $2.58(0.21)$ & $2.59(0.18)$ & $2.56(0.24)$ & $2.55(0.24)$ & $2.58(0.27)$ \\
\hline Aesthetics & $2.89(0.57)$ & $2.89(0.60)$ & $2.99(0.65)$ & $3.01(0.63)$ & $3.11(0.67)$ & $3.10(0.65)$ \\
\hline Safety & $2.87(0.80)$ & $2.89(0.74)$ & $2.89(0.77)$ & $2.93(0.77)$ & $2.98(0.81)$ & $2.97(0.80)$ \\
\hline Social cohesion & $3.27(0.60)$ & $3.14(0.69)$ * & $3.32(0.62)$ & $3.27(0.67)$ & $3.31(0.70)$ & $2.26(0.69)$ \\
\hline Individual & \multicolumn{2}{|c|}{$(n=1,224)$} & \multicolumn{2}{|c|}{$(n=1,203)$} & \multicolumn{2}{|c|}{$(n=1,170)$} \\
\hline Age (years) & $37.8(15.3)$ & $41.8(16.7)$ ** & $36.9(14.6)$ & $41.8(15.8)$ * & 39.7 (15.5) & $42.8(16.2) \star \star$ \\
\hline Time living in neighborhood (years) & $12.1(11.2)$ & $14.1(13.1)$ & $14.8(10.7)$ & $16.4(13.0)$ & $15.1(10.7)$ & $16.8(13.1)$ \\
\hline
\end{tabular}

SD: standard deviation.

* $\mathrm{p}<0.001$;

** $p<0.05$

activity 38,39 and individuals living in high-income neighborhoods have a greater chance of being physically active during leisure 14,37.

Social cohesion is one of the aspects of the social environment, which can influence health and healthy behaviors. It can be understood as the extent of connectivity and solidarity among groups in a society, measured by the levels of trust and reciprocity in the neighborhood 40,41 . Areas or neighborhoods where individuals have more interaction or social cooperation can lead to more efficient use of community resources, such as those meant for the practice of physical activity ${ }^{42}$. Greater social cooperation can also influence people's health, allowing for a diffusion of knowledge of healthy behaviors and lifestyles 43 . It can also promote collective action that reduces crime, insecurity and physical disorder in the neighborhood 40,44.

In this sense, the result of this study corroborates other findings, reinforcing the importance of stimulating social relationships in communities in order to promote the practice of leisuretime physical activity $12,40,42,43,44,45$. Supporting these findings is a review of interventions aiming to increase physical activity showing that interventions providing social support in community environments were effective in increasing physical activity in the population 46 .

However, in our study, the association between leisure-time physical activity and perceptions of social cohesion in the neighborhood was only observed among the low socioeconomic status individuals. Similarly, a study in- cluding 40 socially vulnerable areas of London showed the importance of social support and community networks in practicing leisure-time physical activity among residents over the age of 1643 , suggesting the relevance of this domain in the practice of physical activity in low-income groups. A conceivable explanation for the lack of this association within the medium and high strata of socioeconomic status may be attributed to greater availability of personal and financial resources in either groups, as well as the possibility of living in more favorable places to physical activity or even intermingled in a social environment in which physical activity is recognized by their peers as beneficial to health 29,47 .

Positive associations between leisure-time physical activity and perceived access to services and recreational facilities have been described inconsistently $6,7,8,9,12,14,48,49$, contrasting with our study that failed to find a significant association between the leisure-time physical activity and Services scale, regardless of the socioeconomic status stratum. In the literature available, assessments of services were usually done by measuring either the walking distance needed to access the service or the number of services located in the neighborhood. Distinctly, our study evaluated the service domain using questions where interviewees scored the service available in his/her neighborhood regarding illumination status; street and sidewalk maintenance; public facilities; transportation and traffic quality; law enforcement, and food access. Therefore, in creating a more global evaluation 
Table 3

Prevalence of leisure-time physical activity according to individual characteristics, stratified by socioeconomic status. The BH Health Study, Belo Horizonte, Minas Gerais State, Brazil, 2008-2009.

\begin{tabular}{|c|c|c|c|}
\hline \multirow[t]{3}{*}{ Variables } & \multicolumn{3}{|c|}{ Socioeconomic status } \\
\hline & Low & Medium & High \\
\hline & $\%$ Active $(95 \% \mathrm{Cl})$ & $\%$ Active $(95 \% \mathrm{Cl})$ & $\%$ Active $(95 \% \mathrm{Cl})$ \\
\hline \multicolumn{4}{|l|}{ Gender } \\
\hline Male & $27.2(20.0-34.3) *$ & $30.2(24.8-35.6) * *$ & $46.1(38.5-56.7)$ * \\
\hline Female & $14.8(11.0-18.6)$ & $21.1(16.6-25.7)$ & $35.4(29.7-41.1)$ \\
\hline \multicolumn{4}{|l|}{ Marital status } \\
\hline Without a partner & $20.1(15.2-24.9)$ & $31.3(25.8-36.8)$ * & $45.8(39.2-52.5)$ * \\
\hline With a partner & $20.3(14.9-25.6)$ & $20.1(15.6-24.7)$ & $36.0(30.6-41.5)$ \\
\hline \multicolumn{4}{|l|}{ Currently employed } \\
\hline Yes & $22.5(17.3-27.8)$ * & $23.6(19.6-27.5)$ & $39.9(34.2-45.7)$ \\
\hline No & $15.9(10.6-21.2)$ & $28.8(22.2-35.4)$ & $41.9(34.8-48.9)$ \\
\hline \multicolumn{4}{|c|}{ Regular fruit and vegetable consumption (days/week) } \\
\hline$\geq 5$ & $26.5(20.8-32.2)$ * & $30.6(25.4-35.7)$ * & $43.5(37.5-49.6)$ \\
\hline$<5$ & $16.0(11.4-20.5)$ & $21.0(16.2-25.8)$ & $36.8(30.4-43.2)$ \\
\hline \multicolumn{4}{|l|}{ Current smoker } \\
\hline No & $22.3(17.7-26.8)$ * & $27.7(23.9-31.4) * \star$ & $42.0(36.6-47.3)$ \\
\hline Yes & $13.2(6.7-19.6)$ & $12.7(6.1-19.4)$ & $33.4(23.5-43.2)$ \\
\hline \multicolumn{4}{|l|}{ Alcohol consumption } \\
\hline No & $20.1(15.0-25.3)$ & $22.2(18.4-26.0)$ * & $33.2(27.8-38.5)$ * \\
\hline Yes & $20.4(14.2-26.6)$ & $30.1(24.3-35.8)$ & $45.5(38.8-52.3)$ \\
\hline \multicolumn{4}{|l|}{ Body Mass Index } \\
\hline Underweight & $8.1(1.3-14.9) * \star$ & $25.2(10.3-40.0)$ & $30.7(16.1-45.3)$ \\
\hline Normal weight & $26.2(19.8-32.5)$ & $28.6(22.9-34.3)$ & $45.7(39.0-52.3)$ \\
\hline Overweight & $17.2(12.8-21.5)$ & $22.8(18.4-27.2)$ & $37.4(30.2-44.6)$ \\
\hline \multicolumn{4}{|l|}{ Self-perception of health } \\
\hline Good/Very good & $25.3(19.9-30.8) * \star$ & $28.4(23.9-32.7)$ * & $45.2(40.0-50.5)$ ** \\
\hline Reasonable/Bad/Very bad & $12.5(8.0-17.1)$ & $19.3(14.4-24.2)$ & $24.0(16.8-31.2)$ \\
\hline \multicolumn{4}{|l|}{ Social participation } \\
\hline High & $34.7(25.3-44.1) * \star$ & $39.1(32.1-46.1)$ ** & $49.6(42.6-56.6) * \star$ \\
\hline Medium & $23.1(17.3-29.0)$ & $21.6(16.1-27.1)$ & $34.2(27.3-41.1)$ \\
\hline Low & $11.0(7.5-14.5)$ & $14.8(10.5-19.2)$ & $22.4(15.7-29.0)$ \\
\hline \multicolumn{4}{|l|}{ Physical activity social support } \\
\hline \multicolumn{4}{|l|}{ Ride } \\
\hline Yes & $22.9(17.2-28.7)$ & $29.1(22.9-35.2)$ & $48.4(41.7-55.2) * \star \star$ \\
\hline No & $18.7(14.3-23.1)$ & $23.0(19.9-27.0)$ & $35.9(30.0-41.8)$ \\
\hline \multicolumn{4}{|c|}{ Encouragement from friends or family members ** } \\
\hline Yes & $26.1(20.2-32.1) * \star$ & 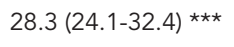 & $44.1(38.8-49.4) * \star \star$ \\
\hline No & $12.3(8.2-16.5)$ & $18.8(13.6-24.1)$ & $29.4(20.8-38.0)$ \\
\hline \multicolumn{4}{|c|}{ Friends or family members' commitment } \\
\hline Yes & $25.5(19.4-31.6)^{\star \star}$ & $30.0(25.2-34.9)$ ** & $42.9(36.6-49.2)$ \\
\hline No & $13.8(9.9-17.6)$ & $18.5(14.7-22.2)$ & $37.3(31.2-68.8)$ \\
\hline
\end{tabular}

95\%Cl: $95 \%$ confidence interval.

${ }^{*} p<0.05$

** $p<0.001$

$* \star *<0.01$. 
Odds ratios of leisure-time physical activity associated with individual and neighborhood characteristics, stratified by socioeconomic status. The $\mathrm{BH}$ Health Study, Belo Horizonte, Minas Gerais State, Brazil, 2008-2009.

\begin{tabular}{|c|c|c|c|c|c|c|}
\hline & \multicolumn{6}{|c|}{ Socioeconomic status } \\
\hline & \multicolumn{2}{|c|}{ Low } & \multicolumn{2}{|c|}{ Medium } & \multicolumn{2}{|c|}{ High } \\
\hline & OR $(95 \% \mathrm{Cl})$ & $p$-value & OR $(95 \% \mathrm{Cl})$ & $p$-value & OR $(95 \% \mathrm{Cl})$ & $p$-value \\
\hline Null model & & $<0.001$ & & $<0.001$ & & $<0.001$ \\
\hline Area level variance (SE) & $0.58(0.22)$ & & $0.51(0.17)$ & & $0.88(0.22)$ & \\
\hline ICC (\%) & 15.01 & & 13.52 & & 21.06 & \\
\hline AIC & 954.48 & & 1314.94 & & 1863.24 & \\
\hline \multicolumn{7}{|l|}{ Model 1} \\
\hline Services & $0.28(0.07-1.04)$ & 0.058 & $2.29(0.82-6.30)$ & 0.110 & $0.67(0.30-1.50)$ & 0.331 \\
\hline Aesthetics & $1.02(0.68-1.52)$ & 0.936 & $0.81(0.55-1.19)$ & 0.281 & $1.29(0.89-1.86)$ & 0.171 \\
\hline Safety & $0.89(0.57-1.36)$ & 0.585 & $0.98(0.76-1.26)$ & 0.854 & $0.96(0.74-1.26)$ & 0.787 \\
\hline Social cohesion & $1.47(1.03-2.08)$ & 0.031 & $1.13(0.80-1.61)$ & 0.485 & $1.05(0.82-1.36)$ & 0.685 \\
\hline Area level variance (SE) & $0.63(0.24)$ & & $0.55(0.19)$ & & $0.88(0.23)$ & \\
\hline ICC (\%) & 16.10 & & 14.33 & & 21,08 & \\
\hline AIC & 947.13 & & 1315.50 & & 1861.14 & \\
\hline \multicolumn{7}{|l|}{ Model 2} \\
\hline Services & $0.24(0.06-1.08)$ & 0.063 & $1.67(0.60-4.69)$ & 0.322 & $0.53(0.23-1.26)$ & 0.154 \\
\hline Aesthetics & $1.14(0.73-1.76)$ & 0.566 & $0.86(0.59-1.26)$ & 0.440 & $1.32(0.93-1.87)$ & 0.118 \\
\hline Safety & $0.98(0.64-1.48)$ & 0.911 & $1.02(0.78-1.33)$ & 0.875 & $0.99(0.76-1.29)$ & 0.972 \\
\hline Social cohesion & $1.45(1.03-2.06)$ & 0.035 & $1.17(0.80-1.72)$ & 0.426 & $1.09(0.82-1.44)$ & 0.550 \\
\hline Area level variance (SE) & $0.64(0.27)$ & & $0.52(0.20)$ & & $0.87(0.23)$ & \\
\hline ICC (\%) & 16.33 & & 13.85 & & 20.85 & \\
\hline AlC & 924.70 & & 1264.58 & & 1825.86 & \\
\hline \multicolumn{7}{|l|}{ Model 3} \\
\hline Services & $0.25(0.06-1.15)$ & 0.075 & $1.54(0.55-4.32)$ & 0.407 & $0.52(0.22-1.23)$ & 0.138 \\
\hline Aesthetics & $1.09(0.68-1.73)$ & 0.727 & $0.83(0.56-1.22)$ & 0.343 & $1.34(0.95-1.89)$ & 0.098 \\
\hline Safety & $1.03(0.71-1.48)$ & 0.888 & $1.01(0.77-1.33)$ & 0.947 & $1.02(0.78-1.34)$ & 0.865 \\
\hline Social cohesion & $1.49(1.03-2.15)$ & 0.036 & $1.12(0.76-1.66)$ & 0.561 & $1.04(0.78-1.39)$ & 0.778 \\
\hline Area level variance (SE) & $0.56(0.24)$ & & $0.64(0.25)$ & & $0.80(0.23)$ & \\
\hline ICC (\%) & 14.60 & & 16.27 & & 19.66 & \\
\hline $\mathrm{AlC}$ & 863.41 & & 1202.83 & & 1765.19 & \\
\hline \multicolumn{7}{|l|}{ Model 4} \\
\hline Services & $0.29(0.07-1.15)$ & 0.079 & $1.20(0.44-3.30)$ & 0.724 & $0.49(0.19-1.22)$ & 0.126 \\
\hline Aesthetics & $1.13(0.74-1.74)$ & 0.565 & $0.84(0.57-1.23)$ & 0.371 & $1.36(0.93-1.98)$ & 0.102 \\
\hline Safety & $1.05(0.71-1.54)$ & 0.801 & $1.05(0.80-1.37)$ & 0.716 & $1.02(0.78-1.34)$ & 0.881 \\
\hline Social cohesion & $1.43(1.02-2.01)$ & 0.039 & $0.98(0.65-1.47)$ & 0.910 & $0.95(0.71-1.27)$ & 0.732 \\
\hline Area level variance (SE) & $0.52(0.23)$ & & $0.54(0.22)$ & & $0.83(0.23)$ & \\
\hline ICC (\%) & 13.58 & & 14.03 & & 20.10 & \\
\hline AIC & 825.45 & & 1176.76 & & 1708.94 & \\
\hline
\end{tabular}

95\% Cl: 95\% confidence interval; AIC: Akaike Information Criterion; ICC: intraclass correlation (latent variable method); OR: odds ratio; SE: standard error. Null model: only the random intercept; Model 1: adjusted for neighborhood variables; Model 2: adjusted for neighborhood variables, time in neighborhood, age, sex, marital status, currently employed; Model 3: adjusted for neighborhood variables, time in neighborhood, age, sex, marital status, currently employed, regular fruit and vegetable consumption; current smoker, alcohol consumption, overweight, self-perception of health; Model 4: adjusted for neighborhood variables, time in neighborhood, age, sex, marital status, currently employed, regular fruit and vegetable consumption, current smoker, alcohol consumption, body mass index, self-perception of health, social participation and physical activity social support. 
of the context related to services, it might seem fractious to contrast our findings with others in the literature.

Another inconsistency encountered in the literature is the relationship between perceived community safety and leisure-time physical activity 6,16,50,51. Comparable to some studies 13,15 we found a non-significant association between leisure-time physical activity and perceived safety, regardless of socioeconomic status. A possible explanation relies on the fact that individuals may practice their physical activity outside their residential area, making neighborhood safety an unrelated variable to the practice of physical activity 6 . However, studies have shown that this association may vary depending on whether safety was measured objectively or subjectively 4652 .

Association between physical activity and aesthetic standards has also shown little consistency 48,49 . Research from Brazil found leisuretime physical activity to have a positive association with the presence of green areas and negative associations with accumulated trash and with physical activity for transportation 11. Yet other national studies did not find significant associations between physical activity and aesthetic standards 12,13 , supporting results found in this current study.

Some methodological issues should be considered when interpreting the results. The lack of an association between leisure-time physical activity and the Services, Aesthetics and Safety scales could be attributed to a lack of heterogeneity in the perceptions of these aspects. We observed a small variation in the mean of the neighborhood scores between active and inactive, as can be seen on Table 2. Alternatively, it should be noted that the physically active participants might practice activities in other locations outside of their home communities leading to a lack of statistical significance in the observations $6,8,50$. Thus, it is important to evaluate the place of physical activity so that the influence of the home environment on these behaviors can be better understood ${ }^{9}$. For example, safety may be an important factor in practicing physical activity in public spaces, but not in closed locations such as gyms, clubs and even in the home, among others 6 .

The scales were constructed based on individual perceptions of the environment, which in turn can be influenced by personal factors and common-source biases 51,52 . However, when using aggregated measures, the error decreases due to the subjectivity of the individuals 52 . Yet, the features of the environment obtained from the individual's perception may differ from those measured by means of objective measures. In
Brazil, the variables based on geographic information system have a limited use due to the limited availability of such data 17 . Furthermore, the use of geographic or administrative units to define a neighborhood, such as the census tract in this study, may go beyond or fall short of what individuals consider as a neighborhood 53 .

It should also be noted that the data from this study, by design, is only from two health districts, namely Barreiro and Oeste. Therefore it may not be representative of the population of Belo Horizonte. Additionally, the cross-sectional design of this study does not allow for the establishment of temporality between exposures and outcomes.

The use of self-reported data, such as reports of physical activity, is susceptible to under or over-reporting of the duration and intensity of the activity. And, even if care was taken to utilize a standardized and an internationally validated questionnaire to determine physical activity, the prevalence of activity can vary according to the version used (short or long), dimensions evaluated (total activity or specific domains) and region surveyed (developed or developing).

On the other hand, it should be noted that the questionnaire used to evaluate the context of the neighborhood was validated for the study population and found to adequately evaluate the properties of the environment of these individuals. Currently, there are few validated instruments adapted to the Brazilian context that assess the specific environment for physical activity 17 , and studies have adapted questions from pre-existing questionnaires 11,12,13,15. Also, the analysis model used (multilevel), adjusted for the main individual factors, known to modulate the associations researched, can be considered the most appropriate for evaluating contextual characteristics. This model allows for the investigation of relative variance at different hierarchical levels and encourages the development of a research hypothesis that examines the role of context 36 . Among the factors of adjustment, the time living in the residence stands out because it can influence the individual's perception of the neighborhood 12 .

\section{Conclusions}

The association found between the Social Cohesion scale and leisure-time physical activity only for the low socioeconomic status stratum, suggests that this domain contributes to the promotion of leisure-time physical activity in economically disadvantaged groups, reinforcing the need to stimulate interventions for enhancing social relationship in this population. 
It is undoubted that determinants of adequate leisure-time physical activity are complex and dependent of individual and contextual factors and may vary greatly between populations. To better understand the benefits of practicing and promoting physical activity in the context of public health it is necessary to explore domains other than leisure, as well as to use both subjective and objective measures (such as GIS and systematic social observation) to evaluate the physical and social environment since each approach can provide additional or different information 54 .

\section{Resumen}

Este estudio tuvo como objetivo estimar la prevalencia de actividad física durante el tiempo libre e investigar su asociación con características contextuales del entorno físico y social en diferentes estatus socioeconómicos, mediante una encuesta de hogares en Belo Horizonte, Minas Gerais, Brasil (2008-2009). Actividad física durante el tiempo libre se midió con el International Physical Activity Questionnaire; y el entorno social y físico por las escalas derivadas de la percepción de atributos del vecindario. El análisis de regresión logística multinivel se realizó por separado para cada estrato socioeconómico. La prevalencia general de actividad física en el tiempo libre fue de un 30,2\%, siendo el 20,2\% en el bajo estatus socioeconómico, el 25,4\% en el medio y el 40,6\% en el alto. Una mayor percepción de la cohesión social se asoció con mayor actividad física en el tiempo libre, sólo para el estatus socioeconómico más bajo, incluso después de ajustarlo según las características individuales. Los resultados demuestran la importancia de la cohesión social para la promoción de actividad física en el tiempo libre en grupos económicamente desfavorecidos, reforzando la necesidad de estimular acciones que puedan mejorar las relaciones sociales en esta población.

Actividad Motora; Actividades Recreativas; Ambiente; Salud Urbana
These findings are preliminary and signal the need for further research on the role of the physical and social environment on the practice of physical activity with the objective of increasing the evidence of these associations, especially in the Brazilian context. They also serve for the elaboration of interventions which promote the practice of physical activity. This study is of particular importance for the development of public policies aimed at increasing the physical activity of certain socioeconomic groups within a city's population in order to prevent an increase of the social inequality gap which harms health.

\section{Contributors}

A. C. S. Andrade and S. V. Peixoto contributed to the literature review, data analysis and writing of the paper. A. A. L. Friche, J. L. Goston, C. C. César and A. V. Diez Roux contributed to the data analysis and the review of the final version of the paper. C. C. Xavier and F. A. Proietti contributed to the study design and the review of the final version of the paper. W. T. Caiaffa contributed to the study design, literature review, data analysis and writing of the paper.

\section{Acknowledgments}

The research team of the Belo Horizonte Observatory for Urban Health of which participated in The $\mathrm{BH} \mathrm{He}$ alth Study; the Graduate Program in Health Sciences of the René Rachou Research Center/Oswaldo Cruz Foundation; CNPq for a research productivity scholarship to the researcher W. T. Caiaffa and S. V. Peixoto. 


\section{References}

1. Bauman AE, Reis RS, Sallis JF, Wells JC, Loos RJ, Martin BW. Correlates of physical activity: why are some people physically active and others not? Lancet 2012; 380:258-71.

2. Hallal PC, Andersen LB, Bull FC, Guthold R, Haskell W, Ekelund U. Global physical activity levels: surveillance progress, pitfalls, and prospects. Lancet 2012; 380:247-57.

3. Hallal PC, Dumith SC, Bastos JP, Reichert FF, Siqueira FV, Azevedo MR. Evolution of the epidemiological research on physical activity in Brazil: a systematic review. Rev Saúde Pública 2007; 41:453-60.

4. World Health Organization. Global strategy on diet, physical activity and health. Geneva: World Health Organization; 2004.

5. World Health Organization. Promoting physical activity and active living in urban environments. Geneva: World Health Organization; 2006.

6. Humpel N, Owen N, Leslie E. Environmental factors associated with adults' participation in physical activity: a review. Am J Prev Med 2002; 22: 188-99.

7. Duncan MJ, Spence JC, Mummery WK. Perceived environment and physical activity: a meta-analysis of selected environmental characteristics. Int J Behav Nutr Phys Act 2005; 2:11.

8. Hoehner CM, Brennan Ramirez LK, Elliott MB, Handy SL, Brownson RC. Perceived and objective environmental measures and physical activity among urban adults. Am J Prev Med 2005; 28(2 Suppl 2):105-16.

9. McGinn AP, Evenson KR, Herring AH, Huston SL, Rodriguez DA. Exploring associations between physical activity and perceived and objective measures of the built environment. J Urban Health 2007; 84:162-84.

10. Saelens BE, Handy SL. Built environment correlates of walking: a review. Med Sci Sports Exerc 2008; 40(7 Suppl):S550-66.

11. Amorim TC, Azevedo MR, Hallal PC. Physical activity levels according to physical and social environmental factors in a sample of adults living in South Brazil. J Phys Act Health 2010; 7 Suppl 2:S204-12.

12. Florindo AA, Salvador EP, Reis RS, Guimaraes VV. Perception of the environment and practice of physical activity by adults in a low socioeconomic area. Rev Saúde Pública 2011; 45:302-10.

13. Hallal PC, Reis RS, Parra DC, Hoehner C, Brownson RC, Simoes EJ. Association between perceived environmental attributes and physical activity among adults in Recife, Brazil. J Phys Act Health 2010; 7 Suppl 2:S213-22.

14. Hino AA, Reis RS, Sarmiento OL, Parra DC, Brownson RC. The built environment and recreational physical activity among adults in Curitiba, Brazil. Prev Med 2011; 52:419-22.

15. Parra DC, Hoehner CM, Hallal PC, Ribeiro IC, Reis R, Brownson RC, et al. Perceived environmental correlates of physical activity for leisure and transportation in Curitiba, Brazil. Prev Med 2011; 52:234-8.
16. Rech CR, Reis RS, Hino AA, Rodriguez-Anez CR, Fermino RC, Goncalves PB, et al. Neighborhood safety and physical inactivity in adults from Curitiba, Brazil. Int J Behav Nutr Phys Act 2012; 9:72.

17. Hino AA, Reis RS, Florindo AA. Ambiente construído e atividade física: uma breve revisão dos métodos de avaliação. Rev Bras Cineantropom Desempenho Hum 2010; 12:387-94.

18. Instituto Brasileiro de Geografia e Estatística. Sinopse do Censo Demográfico, 2010. Rio de Janeiro: Instituto Brasileiro de Geografia e Estatística; 2011.

19. Programa das Nações Unidas para o Desenvolvimento. Atlas de Desenvolvimento Humano do Brasil. http://www.pnud.org.br/atlas/ranking/ Ranking-IDHM-Municipios-2010.aspx (accessed on Jan/2014).

20. Caiaffa WT, Nabuco AL, Friche AAL, Proietti FA. Urban health and governance model in Belo Horizonte, Brazil. In: Vlahov D, Boufford JI, Pearson C, Norris L, editors. Urban health: global perspective. New York: The New York Academy of Medicine; 2010. p. 437-52.

21. Camargos VP, Comini CC, Caiaffa WT, Xavier CC, Proietti FA. Multiple imputation and complete case analysis in logistic regression models: a practical assessment of the impact of incomplete covariate data. Cad Saúde Pública 2011; 27:2299-313.

22. Ferreira AD, Comini CC, Malta DC, Andrade ACS, Ramos CGC, Proietti FA, et al. Validity of data collected by telephone survey: a comparison of VIGITEL 2008 and 'Saúde em Beagá' survey. Rev Bras Epidemiol 2011; 14:16-30.

23. Craig CL, Marshall AL, Sjostrom M, Bauman AE, Booth ML, Ainsworth BE, et al. International physical activity questionnaire: 12-country reliability and validity. Med Sci Sports Exerc 2003; 35:1381-95.

24. Hallal PC, Victora CG, Wells JC, Lima RC. Physical inactivity: prevalence and associated variables in Brazilian adults. Med Sci Sports Exerc 2003; 35:1894-900.

25. World Health Organization. Global recommendations on physical activity for health. Geneva: World Health Organization; 2010.

26. Departamento de Análise de Situação de Saúde, Secretaria de Vigilância em Saúde, Ministério da Saúde. Vigitel Brasil 2012: vigilância de fatores de risco e proteção para doenças crônicas por inquérito telefônico. Brasília: Ministério da Saúde; 2013.

27. Barros AJD, Victora C. Indicador econômico para o Brasil baseado no censo demográfico de 2000. Rev Saúde Pública 2005; 39:523-9.

28. Friche AA, Diez-Roux AV, César CC, Xavier CC, Proietti FA, Caiaffa WT. Assessing the psychometric and ecometric properties of neighborhood scales in developing countries: Saúde em Beagá Study, Belo Horizonte, Brazil, 2008-2009. J Urban Health 2012; 90:246-61.

29. Diez Roux AV, Mair C. Neighborhoods and health. Ann NY Acad Sci 2010; 1186:125-45. 
30. Sallis JF, Cervero RB, Ascher W, Henderson KA, Kraft MK, Kerr J. An ecological approach to creating active living communities. Annu Rev Public Health 2006; 27:297-322.

31. World Health Organization. Physical status: the use and interpretation of anthropometry. Geneva: World Health Organization; 1995.

32. Lipschitz DA. Screening for nutritional status in the elderly. Prim Care 1994; 21:55-67.

33. Lindstrom M, Hanson BS, Ostergren PO. Socioeconomic differences in leisure-time physical activity: the role of social participation and social capital in shaping health related behaviour. Soc Sci Med 2001; 52:441-51.

34. Brownson R, Chang JJ, Eyler A. Saint Louis Environment and Physical Activity Instrument. http:// activelivingresearch.org/files/SLU_SURVEY_0.pdf (accessed on Apr/2012).

35. Merlo J, Chaix B, Ohlsson H, Beckman A, Johnell $\mathrm{K}$, Hjerpe P, et al. Brief conceitual tutorial of multilevel analysis in social epidemiology: using measures of clustering in multilevel logistic regression to investigate contextual phenomena. J Epidemiol Community Health 2006; 60:290-7.

36. Merlo J, Chaix B, Yang M, Lynch J, Ràstam L. A brief conceptual tutorial on multilevel analysis in social epidemiology: interpreting neighbourhood differences and the effect of neighbourhood characteristics on individual health. J Epidemiol Community Health 2005; 59:1022-9.

37. Cerin E, Leslie E. How socio-economic status contributes to participation in leisure-time physical activity. Soc Sci Med 2008; 66:2596-609.

38. Florindo AA, Hallal PC, Moura EC, Malta DC. Practice of physical activities and associated factors in adults, Brazil, 2006. Rev Saúde Pública 2009; 43 Suppl 2:65-73.

39. Knuth AG, Malta DC, Dumith SC, Pereira CA, Morais Neto OL, Temporao JG, et al. Practice of physical activity and sedentarism among Brazilians results of the National Household Sample Survey-2008. Ciênc Saúde Coletiva 2011; 16:3697-705.

40. Cradock AL, Kawachi I, Colditz GA, Gortmaker SL, Buka SL. Neighborhood social cohesion and youth participation in physical activity in Chicago. Soc Sci Med 2009; 68:427-35.

41. Kawachi I, Berkman LF. Social cohesion, social capital and health. In: Berkman LF, Kawachi I, editors. Social epidemiology. New York: Oxford University Press; 2000. p. 174-90.

42. Ball K, Cleland VJ, Timperio AF, Salmon J, GilesCorti B, Crawford DA. Love thy neighbour? Associations of social capital and crime with physical activity amongst women. Soc Sci Med 2010; 71:807-14
43. Yu G, Renton A, Schmidt E, Tobi P, Bertotti M, Watts $\mathrm{P}$, et al. A multilevel analysis of the association between social networks and support on leisure time physical activity: evidence from 40 disadvantaged areas in London. Health Place 2011; 17:1023-9.

44. Fisher KJ, Li F, Michael Y, Cleveland M. Neighborhood-level influences on physical activity among older adults: a multilevel analysis. J Aging Phys Act 2004; 12:45-63.

45. Prince SA, Kristjansson EA, Russell K, Billette JM, Sawada M, Ali A, et al. A multilevel analysis of neighbourhood built and social environments and adult self-reported physical activity and body mass index in Ottawa, Canada. Int J Environ Res Public Health 2011; 8:3953-78.

46. Kahn EB, Ramsey LT, Brownson RC, Heath GW, Howze EH, Powell KE, et al. The effectiveness of interventions to increase physical activity: a systematic review. Am J Prev Med 2002; 22(4 Suppl):73-107.

47. Suzuki CS, Moraes SA, Freitas IC. Physical activity and correlates among adults living in Ribeirao Preto, Southeastern Brazil. Rev Saúde Pública 2011; 45:311-20.

48. Gebel K, Bauman A, Owen N. Correlates of nonconcordance between perceived and objective measures of walkability. Ann Behav Med 2009; 37:228-38

49. Wendel-Vos W, Droomers M, Kremers S, Brug J, van Lenthe F. Potential environmental determinants of physical activity in adults: a systematic review. Obes Rev 2007; 8:425-40.

50. Sallis J, Johnson M, Calfas K, Caparosa S, Nichols J. Assessing perceived physical environmental variables that may influence physical activity. Res Q Exerc Sport 1997; 68:345-51.

51. Duncan G, Raudenbush S. Assessing the effects of context in studies of child and youth development. Educ Psychol 1999; 1:29-41.

52. Mujahid MS, Diez Roux AV, Morenoff JD, Raghunathan T. Assessing the measurement properties of neighborhood scales: from psychometrics to ecometrics. Am J Epidemiol 2007; 165:858-67.

53. Proietti FA, Oliveira DLO, Ferreira AD, Ferreira FR, Caiaffa WT. Unidade de contexto e observação social sistemática em saúde: conceitos e métodos. Physis (Rio J.) 2008; 12:469-82.

54. Echeverria SE, Diez-Roux AV, Link BG. Reliability of self-reported neighborhood characteristics. J Urban Health 2004; 81:682-701.

Submitted on 06/May/2014

Final version resubmitted on $03 / \mathrm{Sep} / 2014$

Approved on 06/Nov/2014 